\title{
Dynamic Economic Dispatch with Valve-Point Effect Using Maclaurin Series Based Lagrangian Method
}

\author{
S. Hemamalini \\ Department of Electrical and Electronics \\ Engineering, \\ National Institute of Technology, \\ Tiruchirappalli-620 015, \\ TamilNadu, India.
}

\author{
Sishaj P Simon \\ Department of Electrical and Electronics \\ Engineering, \\ National Institute of Technology, \\ Tiruchirappalli-620 015, \\ TamilNadu, India.
}

\begin{abstract}
Dynamic Economic Dispatch (DED) plays a vital role in power generation, operation and control. It is a complicated, non-linear constrained problem. In this paper, Maclaurin series based Lagrangian method (MSL) is used to solve the DED problem for generating units with valve-point effect, considering the ramp rate limits. Using Maclaurin series, the sine term used to model the valve-point effect is expanded and solved with Lagrangian method. The feasibility of the proposed method is validated for static economic dispatch problem for forty unit system and DED problem for five unit test system for 24 hour time interval. Results obtained with the proposed approach are compared with other techniques in the literature. The results obtained substantiate the applicability of the proposed method for solving static and dynamic economic dispatch problems with non-smooth cost functions.
\end{abstract}

\section{Keywords}

Dynamic economic dispatch, Lagrangian method, Maclaurin series, ramp rate limits, valve-point loading.

\section{INTRODUCTION}

Dynamic Economic Dispatch is a real time power system problem [1-4]. The output power generation of each unit is determined with respect to predicted load demand over a period satisfying the system constraints and ramp-rate constraint. The basic static economic dispatch problem is to minimize the total generation cost among the committed units satisfying all unit and system equality and inequality constraints. In practical systems, with change in load conditions, the power generation has to be altered to meet the demand. In such cases, static economic dispatch incorporates practical difficulties in the control network.

To overcome this difficulty, dynamic economic dispatch is implemented which takes into account the dynamic costs involved in changing from one-generation level to the other. However, most of them have considered the cost characteristics to be linear in nature in order to simplify the mathematical formulation of the problem and to allow many of the conventional optimization techniques to be used. In reality the input-output characteristic of generating units are non-linear due to valve-point loading and more advanced algorithms are worth developing to obtain accurate dispatch results.

Many works are in literature to solve the DED problem with valve-point loading. There were a number of traditional methods to solve this problem such as, gradient projection algorithm [5], linear programming [6], Lagrangian relaxation [7] and dynamic programming (DP) [8]. In reality, due to valve point effect, the cost function is non-smooth and non-monotonically increasing and traditional methods fail. Over the past few years, in order to solve this problem, many stochastic methods such as genetic algorithm (GA) [9], particle swarm optimization (PSO) [10-12], simulated annealing (SA) [13], and Differential Evolution (DE) [14-15] had been developed. They may prove to be very effective in solving non-convex ED problems without any restriction on the shape of the cost curves. Hybrid methods combining two or more optimization methods were introduced in [16-20] and they prove to be effective in solving the non-smooth DED problem with valve-point effect.

The problem with stochastic search techniques is, they cannot guarantee an optimal or near optimal solution in a single run. Even fixing up the parameters initially cannot guarantee near optimal solution because of the randomness involved in the solution technique. Therefore, the solution obtained is not unique in each trial having a fixed number of iterations. To overcome these problems, Maclaurin series based Lagrangian method is proposed wherein the rectified sinusoid function in the cost equation is represented by Maclaurin sine series approximation and then solved using the Lagrangian method. The approximation error is compensated by an initialization factor, $\mathrm{y}$ which enhances the solution quality. The main advantage in this method is that it has a unique solution unlike in stochastic search techniques as conventional gradient method is used to solve for the optimum generation rather than a population based technique. In addition, this algorithm can provide a more accurate dispatch in few seconds which makes this approach suitable for online dispatch.

\section{PROBLEM FORMULATION}

In dynamic economic dispatch problem, the total fuel cost function associated with the committed units is minimized, taking into consideration the ramp rate constraints of the generating units.

\section{Objective Function}

The fuel cost characteristics of each generating unit $i$, is represented by a quadratic equation, with a sine term added to model the valve-point effect. The DED problem over the stipulated time horizon is formulated as:

Minimize 


$$
\begin{aligned}
& F=\sum_{t=1 i=1}^{T} \sum_{i t}^{N} F_{i t}\left(P_{i t}\right) \\
& =\sum_{s=1}^{J} \sum_{s=1}^{N}\left(\left(a_{s}+b_{s} P_{a}+c_{s} P_{a}\right)+\left|e_{s} \sin \left(f_{s}\left(P_{s \min }-P_{a}\right)\right)\right|_{S / \mathrm{h}}\right.
\end{aligned}
$$

Where $a_{i}, b_{i}, c_{i}$ are the fuel cost coefficients of $i^{\text {th }}$ unit, $e_{i}, f_{i}$ are the valve-point coefficients of $\mathrm{i}^{\text {th }}$ unit, $\mathrm{N}$ is the number of generating units, $\mathrm{P}_{\text {imin }}$ is the minimum generation limit of $\mathrm{i}^{\text {th }}$ unit in $\mathrm{MW}, P_{i t}$ is the power output of $i^{\text {th }}$ unit at time $t$ in $M W, F_{i t}$ is the fuel cost function of $\mathrm{i}^{\text {th }}$ unit in $\$ / \mathrm{h}$ at time $\mathrm{t}, \mathrm{F}$ is the total fuel cost in $\$ / \mathrm{h}$.

This minimization problem is subject to the following constraints:

Equality constraint: Real power balance constraint

$$
\sum_{i=1}^{N} P_{i t}=P_{D t}+P_{L t} \quad t=1,2 \ldots T
$$

Inequality constraint : Real power generation limit

$$
P_{i \min } \leq P_{i t} \leq P_{i \max }
$$

Generating unit ramp rate limit:

$$
\begin{aligned}
& P_{i t}-P_{i(t-1)} \leq U R_{i} \quad i \in N, t \in T \\
& P_{i(t-1)}-P_{i t} \leq D R_{i} \quad i \in N, t \in T
\end{aligned}
$$

$\mathrm{P}_{\mathrm{Dt}}$ is the total load demand in $\mathrm{MW}$ at time $\mathrm{t}, \mathrm{P}_{\mathrm{Lt}}$ is the total transmission loss in $\mathrm{MW}$ at time $\mathrm{t}, \mathrm{P}_{\mathrm{i} \max }$ is the maximum generation limit of $i^{\text {th }}$ unit in MW, $P_{i(t-1)}$ is the power output of $i^{\text {th }}$ unit at time (t-1) in $\mathrm{MW}, \mathrm{UR}_{\mathrm{i}}$ and $\mathrm{DR}_{\mathrm{i}}$ are the up and down ramp rate limits of $\mathrm{i}^{\text {th }}$ unit in $\mathrm{MW} / \mathrm{h}$.

The exact value of system losses can be determined by means of a power flow solution. The most popular approach for finding an approximate value of the losses is by Kron's loss formula as given in (5), which represents the losses as a function of the output level of the system generators.

$$
P_{L t}=\sum_{i=1}^{N} \sum_{j=1}^{N} P_{i t} B_{i j} P_{j t}+\sum_{i=1}^{N} B_{o i} P_{i t}+B_{o o}
$$

Where $B_{i j}, B_{o i}, B_{o o}$ are the transmission loss coefficients.

\section{PROPOSED ALGORITHM}

In reality, to obtain an accurate and practical economic dispatch solution, the valve-point effect is to be considered. In the proposed method the valve-point effect is approximated using Maclaurin sine series expansion in the cost function. The Maclaurin series is mainly used for approximating functions. Here, the expansion technique is used to solve the DED problem with non-linear cost curve. The Maclaurin series expansion for the sine function is given in (6).

$$
\sin x=x-\frac{x^{3}}{3 !}+\frac{x^{5}}{5 !}-\frac{x^{7}}{7 !}+\ldots \ldots
$$

The fuel cost function (1) of unit $i$ is represented as in (7).

$$
\begin{gathered}
F_{i}\left(P_{i}\right)=\left(a_{i}+b_{i} P_{i}+c_{i} P_{i}^{2}\right)+\left|e_{i} \sin x_{i}\right| \\
\text { Where } x_{i}=f_{i}\left(P_{i \text { min }}-P_{i}\right)
\end{gathered}
$$

The level of complexity of the problem increases if higher order terms in (6) are used. So, first two terms of the Maclaurin sine series expansion is considered and is given in (9).

$$
\sin x_{i} \approx x_{i}-\frac{x_{i}^{3}}{3 !}
$$

Substitute $x_{i}$ in (9) and the approximated sine term, $\sin x_{i}$ in (7). Then the cost equation will be as follows:

$$
\begin{aligned}
F_{i}\left(P_{i}\right) & =a_{i}+b_{i} P_{i}+c_{i} P_{i}^{2} \\
& +\varepsilon_{i} f_{i}\left(\frac{f_{i}^{2}}{6} P_{i}^{3}-\frac{f_{i}^{2} P_{i \min }}{2} P_{i}^{2}\right. \\
& \left.+\left(\frac{f_{i}^{2} P_{i \min }^{2}}{2}-1\right) P_{i}+P_{i \text { min }}-\frac{f_{i}^{2} P_{i \text { min }}^{3}}{6}\right) \mid
\end{aligned}
$$

The derivative of (10) which is the incremental cost equation is as given in (11).

$$
\begin{aligned}
& \frac{d F_{i}\left(P_{i}\right)}{d P_{i}}=b_{i}+2 c_{i} P_{i} \\
& +\left|e_{i} f_{i}\left(\frac{f_{i}^{2}}{2} P_{i}^{2}-f_{i}^{2} P_{i \min } P_{i}+\frac{f_{i}^{2} P_{i \min }^{2}}{2}-1\right)\right|
\end{aligned}
$$

By rearranging the terms, (11) can be written in terms of $x_{i}$ as,

$$
\frac{d F_{i}\left(P_{i}\right)}{d P_{i}}=b_{i}+2 c_{i} P_{i}+\left|-e_{i} f_{i}\left(1-\left(x_{i}^{2} / 2 !\right)\right)\right|
$$

Since the sine term is approximated, there will be an approximation error and the solution may not converge to an optimal value. To compensate for the approximation made using Maclaurin sine series expansion and to minimize the error due to approximation, an initialization factor, $y_{i}$ as given in (13) is multiplied to the right hand side of $x_{i}$ in (8). 


$$
y_{i}=\operatorname{real} \frac{\left(\cos -1\left(1-\left(x_{i}^{2}\right) / 2 !+\left(x_{i}^{4} / 4 !\right)\right)\right)}{x_{i}}
$$

The generated power, $P_{i}$ is initially unknown and it can be chosen using (14).

$$
P_{i}=\left(P_{i \max }+P_{i \min }\right) / v
$$

where $v$ is a normalizing factor that normalizes the value of $y_{i}$ between 0 and 1 . Selection of a proper value for $v$ minimizes the error and guarantees an optimal solution for the DED problem. If the $v$ value is fixed properly for any type of system, then optimal or near optimal solution can be obtained by the proposed method. In this paper, $v$ value is determined by trial and error. Multiplying the initialization factor, $y_{i}$ to the right hand side of (8) and then substituting in (12) gives,

$$
\left.\frac{d F_{i}\left(P_{i}\right)}{d P_{i}}=b_{i}+2 c_{i} P_{i}+\mid-e_{i} f_{i}\left(1-y_{i} f_{i}\left(P_{i \min }-P_{i}\right)\right)^{2} / 2 !\right) \mid
$$

\subsection{Maclaurin Sine Series Approximation - With Transmission Losses}

With transmission losses included, using Lagrange multiplier, $\lambda$ the constraints are augmented into objective function as follows:

$$
L=F_{i}\left(P_{i}\right)+\lambda\left(P_{D}+P_{I}-\sum_{i=1}^{N} P_{i}\right)
$$

Partially differentiating (16) with respect to $P_{i}$,

$$
\frac{\partial F_{i}}{\partial P_{i}}+\lambda \frac{\partial P_{L}}{\partial P_{i}}=\lambda
$$

From (5), the incremental transmission loss is obtained as,

$$
\frac{\partial P_{L}}{\partial P_{i}}=2 \sum_{j=1}^{N} B_{i j} P_{j}+B_{o i}
$$

Substitute (15) and (18) in (17) and the modified incremental cost equation can be written as,

$$
\begin{aligned}
& \left.b_{i}+2 c_{i} P_{i}+\mid-e_{i} f_{i}\left(1-y_{i} f_{i}\left(P_{i \text { min }}-P_{i}\right)\right)^{2} / 2 !\right) \mid \\
& +\lambda\left(2 \sum_{j=1}^{N} B_{i j} P_{j}+B_{o i}\right)=\lambda
\end{aligned}
$$

The expression within the vertical bars of (19) can have either positive or negative values. When it is positive, the modified incremental cost equation is as shown in (20).

$$
\begin{aligned}
& \left(-e_{i} f_{i}\left(1-\frac{\left(y_{i} f_{i}\left(P_{i \min }-P_{i}\right)\right)^{2}}{2 !}\right)\right) \\
& =+\left(\lambda-b_{i}-2 c_{i} P_{i}-\lambda\left(2 \sum_{j=1}^{N} B_{i j} P_{j}+B_{o i}\right)\right)
\end{aligned}
$$

Expanding and rearranging (20), the modified incremental cost equation is as shown in (21).

$$
\begin{aligned}
& \frac{e_{i} f_{i}^{3} y_{i}^{2} P_{i}^{2}}{2}+\left(2 c_{i}+2 \lambda B_{i i}-e_{i} f_{i}^{3} y_{i}^{2} P_{i \min }\right) P_{i} \\
& +\left(\begin{array}{l}
\left.2 \lambda \sum_{j=1}^{N} B_{i j} P_{j}+B_{o i} \lambda-e_{i} f_{i}+\frac{e_{i} f_{i}^{3} y_{i}^{2} P_{i \min }^{2}}{2}+b_{i}-\lambda\right)=0 \\
\neq i
\end{array}\right)=0
\end{aligned}
$$

Similarly, when the term within the vertical bars of (19) is negative the incremental cost equation is as shown in (22).

$$
\begin{aligned}
& \left(-e_{i} f_{i}\left(1-\frac{\left(y_{i} f_{i}\left(P_{i \min }-P_{i}\right)\right)^{2}}{2 !}\right)\right) \\
& =-\left(\lambda-b_{i}-2 c_{i} P_{i}-\lambda\left(2 \sum_{j=1}^{N} B_{i j} P_{j}+B_{o i}\right)\right)
\end{aligned}
$$

Expanding and rearranging (22) the modified incremental cost equation is as shown in (23).

$$
\begin{aligned}
& \frac{e_{i} f_{i}^{3} y_{i}^{2} P_{i}^{2}}{2}+\left(-2 c_{i}-2 \lambda B_{i i}-e_{i} f_{i}^{3} y_{i}^{2} P_{i \min }\right) P_{i} \\
& +\left(\begin{array}{c}
\left.-2 \lambda \sum_{j=1}^{N} B_{i j} P_{j}-B_{o i} \lambda-e_{i} f_{i}+\frac{e_{i} f_{i}^{3} y_{i}^{2} P_{i \min }^{2}}{2}-b_{i}+\lambda\right)=0 \\
\neq i
\end{array}\right)=0
\end{aligned}
$$

Equations (21) and (23) are solved for the feasible solution of $P_{i}$ for each unit i. There are four possible roots and only nonnegative real roots are considered. The feasible power output of a unit can be selected as the maximum non-negative real root. Once $\mathrm{P}_{\mathrm{i}}$ value is determined, then the solution is obtained by an iterative procedure and the process is continued until $\Delta \mathrm{P}$ is within a specified accuracy. Lambda value for each unit $\mathrm{i}$ can be obtained by rearranging (21) and is given in (24). 


$$
\frac{\frac{e_{i} f_{i}^{3} y_{i}^{2} P_{i}^{2}}{2}+\left(2 c_{i}-e_{i} f_{i}^{3} y_{i}^{2} P_{i \min }\right) P_{i}+\left(b_{i}-e_{i} f_{i}+\frac{e_{i} f_{i}^{3} y_{i}^{2} P_{i \min }^{2}}{2}\right)}{1-2 \sum_{j=1}^{N} B_{i j} P_{j}-B_{o i}}
$$

The initial lambda value can be calculated by taking the mean of the lambda values for all the units. If $\Delta \mathrm{P}$ is not within a specified accuracy then determine $\Delta \lambda$ to increment or decrement lambda. Using the gradient method as described in [21], the value of $\Delta \lambda$ is found and it is given as

$$
\Delta \lambda=\frac{\Delta \mathrm{P}}{\left|\sum\left(\mathrm{dP}_{\mathrm{i}} / \mathrm{d} \lambda\right)\right|}
$$

where $\Delta \mathrm{P}$ is the difference between the sum of generation of all the units in a particular interval and the demand plus transmission losses at that interval. To obtain the derivative of power output of unit $\mathrm{i}$ with respect to lambda, the expression for output power generation for each unit is obtained from (21).

\subsection{Algorithm for DED Problem Using the Proposed MSL Method}

The step-by-step algorithm for dynamic economic load dispatch with losses is as follows:

Step 1: Input the cost coefficients of generators, power generation limits, ramp rate limits, number of intervals, load demand for each interval and transmission loss coefficients.

Step 2: Initial power generation for each unit is taken as the mean of its minimum and maximum generation limits. Select properly tuned value for normalizing factor $v$. Calculate $\lambda$ for each generating unit using (24) and the initial lambda value by taking the mean of lambda values for all the units. Calculate the initialization factor, $y_{i}$ using (13). The initialization factor is fixed at the start of the iteration for each interval and remains constant throughout the run.

Step 3: Obtain B-loss coefficients using Newton-Raphson power flow solution to calculate the transmission losses in cases where losses of the system are taken into consideration.

Step 4: Compute the generator power output $\mathrm{P}_{\mathrm{i}}$, for each generating unit $i$, using (21). Select feasible value for $P_{i}$ as discussed in section 3.1 .

Step 5: Check for the power generation and ramp rate limits for each generating unit.

Step 6: Evaluate the error between the demand, transmission power loss and sum of power output from all the units i using $\varepsilon=\left(P_{D t}+P_{L t}-\sum_{i=1}^{N} P_{i t}\right)$.
Step 7: If the error is greater or lesser than the set tolerance, decrement or increment the $\lambda$ value respectively using $\Delta \lambda$ in (25) and go to step 4 . This process is continued until $\Delta \mathrm{P}$ is less than a specified set tolerance. In this paper, it has been set as 0.0001 . Else, go to step 8.

Step 8: If number of hours specified is not reached repeat steps 27. Else, go to step 9.

Step 9: Compute the total cost for all the intervals and stop the iteration.

The flowchart for the proposed MSL algorithm is shown in Figure 1.

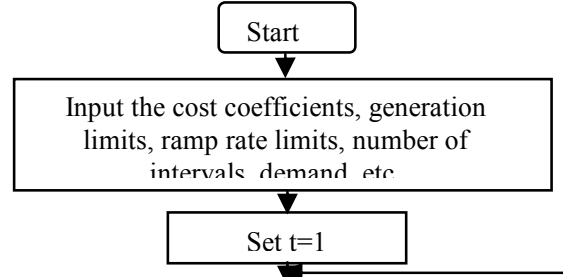

Select proper value of normalizing factor $v$ and calculate initialization factor, $y_{i}$ using (13) and lambda value using (24)

Obtain B-loss coefficients from Newton -Raphson power flow solution and

Calculate $P_{i}$ using (21) and (23) for $i=1,2 \ldots N$

Check for generation limits and if any generating unit violates the constraint set to the minimum or maximum li

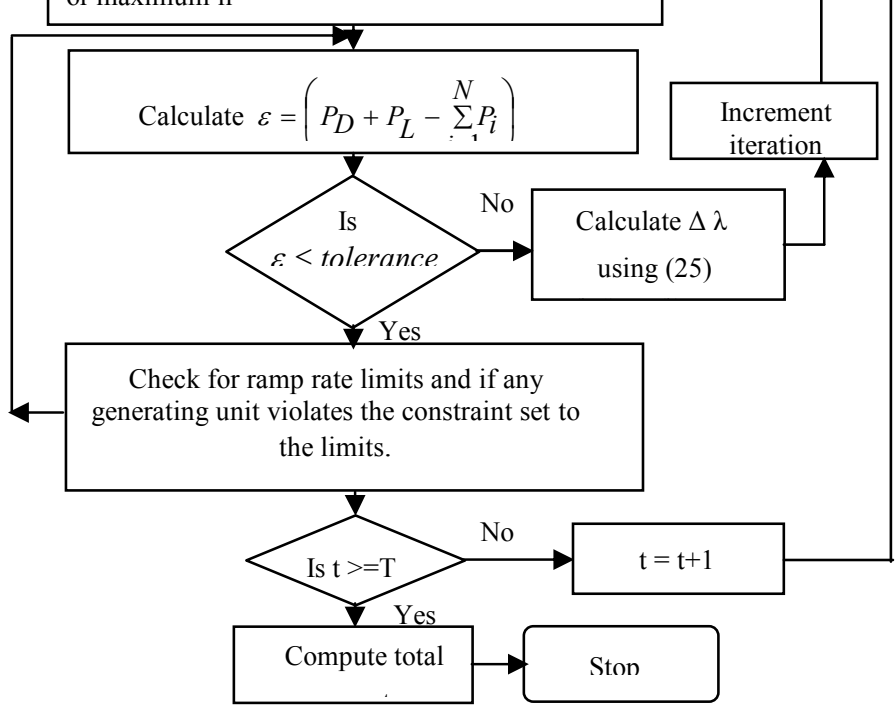

Figure 1. Flowchart for the proposed MSL method.

\section{RESULTS AND DISCUSSIONS}

The effectiveness of the proposed MSL method for practical applications is tested on two different test cases. Case 1 is a fortyunit system for which static economic dispatch is performed neglecting the dynamic constraints. In case 2 a five-unit system is considered for which dynamic economic dispatch is performed 
considering dynamic constraints for 24 hour interval. In both the cases, valve-point effect is included. Transmission losses are included in case 2 alone.

MATLAB codes have been developed to perform the above tasks and executed on $3.2 \mathrm{GHz}$, Pentium IV processor, 1 GB RAM PC. The convergence criterion for the test cases is based on the error in the power balance constraint. The tolerance of the error is set as 0.0001 . The value of normalizing factor $v$, is tuned for each load condition to obtain the optimum generation, satisfying the power generation limits and ramp-rate limits. The value of $v$ is set by varying it from 1 to 10 in steps and the $v$ value that yields minimum cost is set as the normalizing factor for that load condition.

\subsection{Case 1: Static ED to validate the proposed method for forty unit system}

In this case, to validate the applicability of the proposed method, 40-unit system [22] is solved for static conditions neglecting dynamic constraints. Cost curves include valve-point effects and the test data are adapted from [22]. This being a larger system the number of local minima will be more. Transmission losses are neglected in this case. The total demand is set at 10,500 MW. Results obtained for v value of 3.948 and calculated lambda value of 0.96263 are given in Table 1 and it shows that the proposed MSL method is feasible and capable of acquiring better solution. Total cost obtained using the proposed method is $\$ 1,22,406.10$ and the optimal generation of each unit is within their minimum and maximum generation limits. Table 2 shows the mean and best time, minimum and maximum costs acquired by other methods in literature.

Though the cost reported in [29] is minimum, the cost obtained using the proposed method is comparable with the mean and maximum costs in all the other methods shown in Table 2. Also, the best time for obtaining the best solution for all the other techniques given in Table 2 is indicative of the fact that time taken by the proposed method to converge to the near optimal solution is very much less. The main advantage of the proposed method is the computation time with solutions at par with other techniques.Convergence characteristics of total cost are shown in Fig. 2.

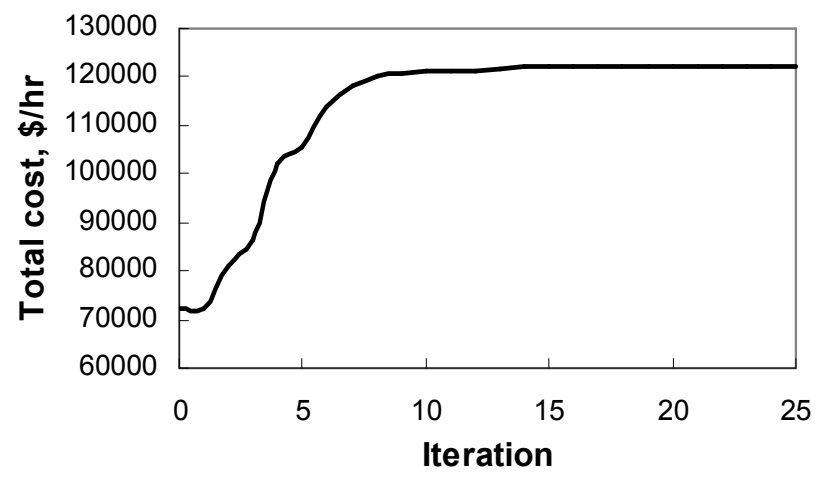

TABLE 1

RESULT FOR 40 GENERATING UNITS-CASE 1

\begin{tabular}{|c|c|c|c|}
\hline Unit & Pmin (MW) & Generation (MW) & Pmax (MW) \\
\hline 1 & 36 & 114.00 & 114 \\
\hline 2 & 36 & 114.00 & 114 \\
\hline 3 & 60 & 60.00 & 120 \\
\hline 4 & 80 & 190.00 & 190 \\
\hline 5 & 47 & 97.00 & 97 \\
\hline 6 & 68 & 68.00 & 140 \\
\hline 7 & 110 & 300.00 & 300 \\
\hline 8 & 135 & 300.00 & 300 \\
\hline 9 & 135 & 300.00 & 300 \\
\hline 10 & 130 & 130.00 & 300 \\
\hline 11 & 94 & 94.00 & 375 \\
\hline 12 & 94 & 94.00 & 375 \\
\hline 13 & 125 & 125.00 & 500 \\
\hline 14 & 125 & 394.28 & 500 \\
\hline 15 & 125 & 394.30 & 500 \\
\hline 16 & 125 & 394.30 & 500 \\
\hline 17 & 220 & 491.00 & 500 \\
\hline 18 & 220 & 491.01 & 500 \\
\hline 19 & 242 & 513.80 & 550 \\
\hline 20 & 242 & 513.80 & 550 \\
\hline 21 & 254 & 530.13 & 550 \\
\hline 22 & 254 & 530.13 & 550 \\
\hline 23 & 254 & 530.16 & 550 \\
\hline 24 & 254 & 530.16 & 550 \\
\hline 25 & 254 & 530.06 & 550 \\
\hline 26 & 254 & 530.06 & 550 \\
\hline 27 & 10 & 10.00 & 150 \\
\hline 28 & 10 & 10.00 & 150 \\
\hline 29 & 10 & 10.00 & 150 \\
\hline 30 & 47 & 97.00 & 97 \\
\hline 31 & 60 & 190.00 & 190 \\
\hline 32 & 60 & 190.00 & 190 \\
\hline 33 & 60 & 190.00 & 190 \\
\hline 34 & 90 & 200.00 & 200 \\
\hline 35 & 90 & 200.00 & 200 \\
\hline 36 & 90 & 200.00 & 200 \\
\hline 37 & 25 & 110.00 & 110 \\
\hline 38 & 25 & 110.00 & 110 \\
\hline 39 & 25 & 110.00 & 110 \\
\hline 40 & 242 & 513.80 & 550 \\
\hline
\end{tabular}

Figure 2. Convergence of total cost for forty unit system- Case 1. 
TABLE 2

COMPARISON OF RESULTS -CASE 1 LOAD $=10500 \mathrm{MW}$

\begin{tabular}{|c|c|c|c|c|c|}
\hline Method & $\begin{array}{c}\text { Mean } \\
\text { time } \\
(\mathrm{sec})\end{array}$ & $\begin{array}{c}\text { Best time } \\
(\mathrm{sec})\end{array}$ & $\begin{array}{l}\text { Mean cost } \\
(\$ / \mathrm{h})\end{array}$ & $\begin{array}{l}\text { Maximum } \\
\operatorname{cost}(\$ / \mathrm{h})\end{array}$ & $\begin{array}{l}\text { Minimum } \\
\operatorname{cost}(\$ / h)\end{array}$ \\
\hline CEP [22] & 1956.9 & 1955.2 & 124793.5 & 126902.9 & 123488.29 \\
\hline FEP [22] & 1039.1 & 1037.9 & 124119.4 & 127245.6 & 122679.71 \\
\hline MFEP [22] & 2196.1 & 2194.7 & 123489.7 & 124356.5 & 122647.57 \\
\hline IFEP [22] & 1167.3 & 1165.7 & 123382.0 & 125740.6 & 122624.35 \\
\hline EP-SQP[23] & 997.73 & - & 122379.6 & - & 122323.97 \\
\hline PSO [23] & 933.39 & - & 124154.5 & - & 123930.45 \\
\hline $\begin{array}{l}\text { PSO-SQP } \\
{[23]}\end{array}$ & 733.97 & - & 122245.3 & - & 122094.67 \\
\hline $\begin{array}{l}\text { NPSO-LRS } \\
{[24]}\end{array}$ & 3.93 & - & 122209.3 & 122981.7 & 121664.43 \\
\hline MPSO[25] & - & - & - & - & 122252.27 \\
\hline $\mathrm{ESO}[26]$ & - & 0.261 & 122524.1 & 123143.1 & 122122.16 \\
\hline $\begin{array}{l}\mathrm{DEC}(2)- \\
\mathrm{SQP}(1)[27]\end{array}$ & 14.26 & - & 122295.1 & 122839.3 & 121741.98 \\
\hline TM [28] & 94.28 & 91.16 & 123078.2 & 124693.8 & 122477.78 \\
\hline PS[29] & 42.98 & 12.66 & 122332.7 & 125486.3 & 121415.14 \\
\hline MSL & - & 0.078 & - & - & 122406.1 \\
\hline
\end{tabular}

\subsection{Case 2: Five-unit system}

In this case, the DED problem of a 5-unit system is solved by considering the transmission losses. Unit data and load pattern for case 2 is adapted from [13] and shown in Table 3 and Table 4. The transmission loss coefficients are taken from [13] and are given in (26).

$\mathrm{B}=\left[\begin{array}{lllll}0.000049 & 0.000014 & 0.000015 & 0.000015 & 0.000020 \\ 0.000014 & 0.000045 & 0.000016 & 0.000020 & 0.000018 \\ 0.000015 & 0.000016 & 0.000039 & 0.000010 & 0.000012 \\ 0.000015 & 0.000020 & 0.000010 & 0.000040 & 0.000014 \\ 0.000020 & 0.000018 & 0.000012 & 0.000014 & 0.000035\end{array}\right]$

TABLE 3

GENERATOR DATA-CASE 2-FIVE-UNIT SYSTEM

\begin{tabular}{lccccc}
\multicolumn{5}{c}{ GENERATOR DATA-CASE 2-FIVE-UNIT SYSTEM } \\
\hline & Unit 1 & Unit 2 & Unit 3 & Unit 4 & Unit 5 \\
\hline $\mathrm{a}_{\mathrm{i}}(\$ / \mathrm{h})$ & 25 & 60 & 100 & 120 & 40 \\
$\mathrm{~b}_{\mathrm{i}}(\$ / \mathrm{MWh})$ & 2.0 & 1.8 & 2.1 & 2.0 & 1.8 \\
$\mathrm{c}_{\mathrm{i}}\left(\$ \mathrm{MW}^{2} \mathrm{~h}\right)$ & 0.0080 & 0.0030 & 0.0012 & 0.0010 & 0.0015 \\
$\mathrm{e}_{\mathrm{i}}(\$ / \mathrm{h})$ & 100 & 140 & 160 & 180 & 200 \\
$\mathrm{f}_{\mathrm{i}}(1 / \mathrm{MW})$ & 0.042 & 0.040 & 0.038 & 0.037 & 0.035 \\
$\mathrm{P}_{\text {imin }}(\mathrm{MW})$ & 10 & 20 & 30 & 40 & 50 \\
$\mathrm{P}_{\text {imax }}(\mathrm{MW})$ & 75 & 125 & 175 & 250 & 300 \\
$\mathrm{UR}(\mathrm{MW} / \mathrm{h})$ & 30 & 30 & 40 & 50 & 50 \\
$\mathrm{DR}(\mathrm{MW} / \mathrm{h})$ & 30 & 30 & 40 & 50 & 50 \\
\hline
\end{tabular}

TABLE 4

LOAD DEMAND FOR 24 HOURS-CASE 2-FIVE-UNIT SYSTEM

\begin{tabular}{cccccccc}
\hline Hour & $\begin{array}{c}\text { Load } \\
(\mathrm{MW})\end{array}$ & Hour & $\begin{array}{c}\text { Load } \\
(\mathrm{MW})\end{array}$ & Hour & $\begin{array}{c}\text { Load } \\
(\mathrm{MW})\end{array}$ & Hour & $\begin{array}{c}\text { Load } \\
(\mathrm{MW})\end{array}$ \\
\hline 1 & 410 & 7 & 626 & 13 & 704 & 19 & 654 \\
2 & 435 & 8 & 654 & 14 & 690 & 20 & 704 \\
3 & 475 & 9 & 690 & 15 & 654 & 21 & 680 \\
4 & 530 & 10 & 704 & 16 & 580 & 22 & 605 \\
5 & 558 & 11 & 720 & 17 & 558 & 23 & 527 \\
6 & 608 & 12 & 740 & 18 & 608 & 24 & 463
\end{tabular}

The optimal power dispatch of units over a 24-hour time horizon is shown in Table 5. Table 6 gives a comparison of the costs obtained from various techniques reported in the literature. However, the total cost is higher when compared to SA and less than that of PSO. Though the cost is higher, the solution obtained using the proposed MSL method is unique in nature and the computational time is $1.48 \mathrm{~s}$, which is very small when compared to the other two methods. It can be inferred from the results that the solution obtained from the proposed method is at par with other techniques in literature. Though global optima is desirable, in most practical purposes near optimal solution, which is consistent, is generally sufficient.

TABLE 5

GENERATION SCHEDULE USING MSL METHOD-CASE 2-FIVE UNIT SYSTEMWITH LOSS

\begin{tabular}{|c|c|c|c|c|c|c|}
\hline Hour & $\begin{array}{c}\text { Normalizing } \\
\text { factor, } v\end{array}$ & $\begin{array}{c}\mathrm{P}_{1} \\
(\mathrm{MW})\end{array}$ & $\begin{array}{c}\mathrm{P}_{2} \\
(\mathrm{MW})\end{array}$ & $\begin{array}{c}\mathrm{P}_{3} \\
(\mathrm{MW})\end{array}$ & $\begin{array}{c}\mathrm{P}_{4} \\
(\mathrm{MW})\end{array}$ & $\begin{array}{c}\mathrm{P}_{5} \\
(\mathrm{MW})\end{array}$ \\
\hline 1 & 7.57 & 10.00 & 20.00 & 117.30 & 126.39 & 139.78 \\
\hline 2 & 3.61 & 40.00 & 50.00 & 77.30 & 124.55 & 147.10 \\
\hline 3 & 1.81 & 10.00 & 80.00 & 117.30 & 118.96 & 153.46 \\
\hline 4 & 1.81 & 10.00 & 68.66 & 157.30 & 132.40 & 167.47 \\
\hline 5 & 1.63 & 10.00 & 98.66 & 117.30 & 121.23 & 217.47 \\
\hline 6 & 1.72 & 10.00 & 93.50 & 157.30 & 144.41 & 210.56 \\
\hline 7 & 1.63 & 10.00 & 123.50 & 117.30 & 123.22 & 260.56 \\
\hline 8 & 1.27 & 10.00 & 125.00 & 123.60 & 173.22 & 231.41 \\
\hline 9 & 2.17 & 10.00 & 95.00 & 139.33 & 223.22 & 232.66 \\
\hline 10 & 1.36 & 10.00 & 125.00 & 100.14 & 250.00 & 229.89 \\
\hline 11 & 2.17 & 10.00 & 95.00 & 140.14 & 250.00 & 236.05 \\
\hline 12 & 1.72 & 27.44 & 114.76 & 175.00 & 200.00 & 234.32 \\
\hline 13 & 2.26 & 10.00 & 84.76 & 175.00 & 250.00 & 234.95 \\
\hline 14 & 1.72 & 11.17 & 98.24 & 175.00 & 200.00 & 215.62 \\
\hline 15 & 1.72 & 16.12 & 101.58 & 175.00 & 150.93 & 219.34 \\
\hline 16 & 2.71 & 12.48 & 71.58 & 135.00 & 132.84 & 235.22 \\
\hline 17 & 2.26 & 10.00 & 52.17 & 95.00 & 182.84 & 224.73 \\
\hline 18 & 2.26 & 10.00 & 53.11 & 92.65 & 232.84 & 227.56 \\
\hline 19 & 1.36 & 10.00 & 83.11 & 96.00 & 250.00 & 224.37 \\
\hline 20 & 1.36 & 10.00 & 113.11 & 105.14 & 250.00 & 236.71 \\
\hline 21 & 1.72 & 18.69 & 103.98 & 145.14 & 200.00 & 221.99 \\
\hline 22 & 2.08 & 17.98 & 73.98 & 135.33 & 207.53 & 177.91 \\
\hline
\end{tabular}




\begin{tabular}{|c|c|c|c|c|c|c|}
\hline 23 & 1.90 & 10.00 & 47.69 & 175.00 & 157.53 & 142.55 \\
\hline 24 & 1.99 & 10.00 & 32.03 & 175.00 & 119.76 & 130.67 \\
\hline \multicolumn{7}{|c|}{ TABLE 6} \\
\hline \multirow{2}{*}{\multicolumn{2}{|c|}{ Solution Technique }} & \multicolumn{3}{|c|}{ Production cost, $\$$} & \multirow{2}{*}{\multicolumn{2}{|c|}{$\begin{array}{l}\text { Computing } \\
\text { time, } s\end{array}$}} \\
\hline & & Best $\mathrm{v}$ & & Mean value & & \\
\hline \multicolumn{2}{|c|}{$\begin{array}{l}\text { Simulated } \\
\text { Annealing [13] }\end{array}$} & 47,35 & & - & & 351.98 \\
\hline \multicolumn{2}{|c|}{ PSO [11] } & 50,12 & & - & & 258.00 \\
\hline \multicolumn{2}{|c|}{ MSL } & 49,21 & & - & & 1.48 \\
\hline
\end{tabular}

Unlike in any other stochastic algorithms, MSL method has only one parameter to be tuned and set before starting the iterative process. In future, proper tuning of the normalizing factor, $v$ can be achieved using suitable algorithms, replacing the trial and error method. In addition, constraints that are more realistic will be incorporated to the problem structure. This method may prove itself in terms of time and solution uniqueness in a deregulated environment, where minute-by-minute dispatch is done and where profit of the generating companies (GENCOs) is the main consideration.

\section{CONCLUSION}

This paper proposed a Maclaurin series based Lagrangian method to solve the DED problem with valve-point effect. An attempt is made to find the optimal or near optimal solution by approximating the cost curve with valve-point effect. The feasibility of the proposed method for solving DED problems is demonstrated using five and forty unit systems. For comparison with literature results, 24-hour dispatch is done for five-unit system. Also for a large system of forty units, static economic dispatch is done to validate the proposed method. The comparison of the results with other methods reported in the literature validates the capability of the proposed method for solving nonsmooth DED problems in a power system. The method is simple, easy to implement, convergence rate is fast and the computational time is less. The performance of this approach is better in exhibiting the consistency of reaching the near global optima and the guarantee on solution quality obtained without violating the constraints. The proposed method is a generalized approach, which can be extended to any test systems. In addition, the method is robust and more consistent in producing optimal solution, unlike the stochastic methods as they typically identify a different solution each time they are applied.

\section{REFERENCES}

[1] Bechert, T.E., and Kwatny, H.G., "On the optimal dynamic dispatch of real power," IEEE Trans., vol. PAS-91, pp. 889898, 1972.

[2] Ross, D.W., and Kim, S. "Dynamic Economic Dispatch of Generation," IEEE Transactions on Power Apparatus and Systems, vol. PAS-99, pp.2060-2068, Nov/Dec 1980.

[3] Wood, W. G., "Spinning reserve constrained static and dynamic economic dispatch", IEEE Trans. on Power Apparatus and Systems, vol. PAS-101, pp. 381-388, February 1982.
[4] Wang, C., Shahidehpour, S.M., "Effects of ramp rate limits on unit commitment and economic dispatch" IEEE Trans. on Power Syst., vol. 8, August 1993.

[5] Granelli, G. P., Marannino, P., Montagna, M., and Silvestri, A., "Fast and efficient gradient projection algorithm for dynamic generation dispatching," IEE Proc. Gener. Transm. Distrib., vol. 136, pp. 295-302, September 1989.

[6] Somuah, C.B. and Khunaizi, N., "Application of Linear programming re-dispatch technique to Dynamic Generation allocation", IEEE Trans. on Power Syst., vol.5, pp. 2026,1990 .

[7] Hindi, K. S., and Ab Ghani,M. R., "Dynamic economic dispatch for large scale power systems: A Lagrangian relaxation approach," Elect. Power Syst. Res., vol. 13, pp. 51-56, 1991.

[8] Travers, D.L., Kaye, R.J., "Dynamic dispatch by constructive dynamic programming," IEEE Trans. on Power Syst., vol.13, pp.72-78, Feb 1998.

[9] Li, F., Morgan, R., and Williams, D., "Hybrid genetic approaches to ramping rate constrained dynamic economic dispatch," Elect. Power Syst. Res., vol. 43, pp. 97-103, 1997.

[10] Victoire, T. A. A., and Jeyakumar, A. E., "Deterministically guided PSO for dynamic dispatch considering valve-point effects," Elect. Power Syst. Res., vol. 73, pp. 313-322, 2005.

[11] Chakrabarti, R., Chattopadhyay, P. K., Basu, M., and Panigrahi, C. K., "Particle swarm optimization technique for dynamic economic dispatch," Institute of Engineers (India), pp.48-54, July 2005.

[12] Panigrahi, B. K., Ravikumar Pandi, V., and Sanjoy Das, "Adaptive particle swarm optimization approach for static and dynamic economic load dispatch," Energy conversion and management, vol. 49, pp. 1407-1415, February 2008.

[13] Panigrahi, C. K., Chattopadhyay, P. K., Chakrabarti, R. N., and Basu, M. "Simulated annealing technique for dynamic economic dispatch," Electric Power Components and Systems, vol. 34, pp. 577-586, 2006.

[14] Balamurugan, R. and Subramanian, S., "Differential Evolution-based Dynamic Economic Dispatch of Generating Units with Valve-point Effects," Electric Power Components and Systems, vol. 36, pp. 828-843, August 2008.

[15] Xiaohui Yuan, Liang Wang, Yanbin Yuan, Yongchuan Zhang, Bo Cao, and Bo Yang, "A modified differential evolution approach for dynamic economic dispatch with valve point effects," vol. 49, pp.3447-3453, September 2008.

[16] Mekhamer, S. F., Abdelaziz, A. Y., Kamh, M. Z. and Badr, M. A. L., "Dynamic Economic Dispatch Using a Hybrid Hopfield Neural Network Quadratic Programming Based Technique," Electric Power Components and Systems, vol. 37, pp. 253 -264, March 2009.

[17] Attaviriyanupap, P., Kita, H., Tanaka, E., and Hasegawa, J.: 'A hybrid EP and SQP for dynamic economic dispatch with nonsmooth incremental fuel cost function', IEEE Trans. Power Syst., vol. 17, pp. 411-416, 2002. 
[18] Victoire, T.A.A., and Jeyakumar, A.E., "Reserve constrained dynamic dispatch of units with valve-point effects," IEEE Trans. Power Syst., vol. 20, pp. 1272-1282, 2005.

[19] Victoire, T. A. A., and Jeyakumar, A. E., "Hybrid PSO-SQP for economic dispatch with valve-point effect," Electric Power Systems Research, vol. 71, pp. 51-59, 2004.

[20] Victoire, T. A. A., and Jeyakumar, A. E., “A modified hybrid EP-SQP approach for dynamic dispatch with valve-point effect," Elect. Power Energy Syst., vol. 24, No. 10, pp. 723729, 2005.

[21] Hadi Saadat, Power System Analysis, 2nd ed. New York: McGraw-Hill, 2002.

[22] N. Sinha, R. Chakrabarti, and P. K. Chattopadhyay, Evolutionary programming techniques for economic load dispatch, IEEE Trans. Evol. Comput. 7 (2003) 83-94.

[23] Victorie, T. A. A., and Jeyakumar, A.E.: 'Hybrid PSO-SQP for economic dispatch with valve-point effect', Elect. Power Syst. Res., 2004, 71, (1), pp. 51-59.

[24] Immanuel Selvakumar, A. and Thanushkodi, K.: ‘ A new particle swarm optimization solution to economic dispatch problems', IEEE Trans. Power Syst., 2007, 22, (1), pp. 4251 .
[25] Park, J. B., Lee, K. S., Shin, J. R., and Lee, K. Y.: 'A particle swarm optimization for economic dispatch with nonsmooth cost function', IEEE Trans. Power Syst., 2005, 20, (1), pp. 34-42.

[26] Pereira-Neto, A., Unsihuay, C., and Saavedra, O.R., 'Efficient evolutionary strategy optimization procedure to solve the nonconvex economic dispatch problem with generator constraints', IEE proc.- Gener. Transm. and Distrib., 2005, 152, (5), pp. 653-660.

[27] Coelho, Ld. S., and Mariani, V.C.: 'Combining of chaotic differential evolution and quadratic programming for economic dispatch optimization with valve-point effect', IEEE Trans. Power Syst., 2006, 21, (2), pp. 989-996.

[28] Liu, D. and Cai, Y.: 'Taguchi method for solving the economic dispatch problem with nonsmooth cost functions', IEEE Trans. Power Syst., 2005, 20, (4), pp. 2006-2014.

[29] Al-Sumait, J.S., Al-Othman, A.K., and Sykulski, J.K.: 'Application of pattern search method to power system valve-point economic load dispatch', Elect. Power Syst. Res., 2007, 29, (10), pp. 720-730. 